\title{
The influence of coupling on the whole process of construction simulation of chord dome structure
}

\author{
Jing Liu ${ }^{l}$, Fei Meng ${ }^{l}$, Yingqi $\mathrm{Chen}^{l}$, and Zongxue $\mathrm{Chen}^{2}$ \\ ${ }^{1}$ College of Civil Engineering and Architecture, Hebei University, Baoding, Hebei, 071002, China \\ ${ }^{2}$ Hebei construction group corporation limited, Baoding, Hebei, 071052,China
}

\begin{abstract}
Chord dome structure is a new type of hybrid prestressed spatial steel structure system, which is often used in large-span structures. During the construction of the structure, it is necessary to apply prestress to the ring cable. Taking the chord dome roof of Hebei North University gymnasium as an example, the whole process of prestressed cable construction is simulated and analyzed by using the finite element software ANSYS. The hoop cable of the dome roof can slide freely in the hoop direction, and the attribute of free sliding in the ANSYS interface is "coupling". In this paper, two kinds of simulation models, coupling and uncoupling, are established to compare, and then to explore the influence of coupling on the construction process of string dome structure.
\end{abstract}

\section{Introduction}

With the development of new technology and the improvement of building level, the long-span prestressed spatial steel structure, such as chord dome structure, has developed rapidly as a new force[1].The system can greatly reduce the amount of steel used, give full play to the strength of steel in the space stress, have a variety of forms in the building configuration, and have a good visual effect, so it is widely used in engineering[2-5].In this paper, the whole process of prestressed cable construction in Hebei North University Gymnasium is simulated and analyzed.

The gymnasium of Hebei North University covers an area of $11390 \mathrm{~m}^{2}$, with a total building area of $26352.4 \mathrm{~m}^{2}$. The plane projection of the roof is a kind of round rectangle with double axis symmetry. The plane dimensions are $90.99 \mathrm{~m}$ for the long axis, $83.74 \mathrm{~m}$ for the short axis, and $6.558 \mathrm{~m}$ for the roof. The chord dome roof is composed of the upper single-layer latticed shell and the lower cable support system. The upper single-layer latticed shell adopts the grid form of Kiewitt type [6],The lower chord support system is levy system, which is composed of five rings of circumferential cables, six rings of radial steel tie rods and vertical braces.

\section{Finite element model}

In this project, ANSYS10.0 is used to carry out virtual tension analysis on the tension construction process. In the establishment of the finite element model, according to the actual conditions, the actual size of the components is used. The upper single-layer latticed shell adopts the beam 188 unit, the radial pull rod and the vertical strut adopt the link 8 unit, the circumferential cable adopts the link 10 which is only tension and not compression, and the full scaffold adopts the link 10 which is only compression and not tension. In this paper, many factors are considered, the construction method of tension ring cable is selected, and the "kill" and "activate" functions of element life and death method are used to realize the prestressing of ring cable according to the construction sequence. The material characteristics of the model are shown in Table 1. The established simulation model is shown in Fig. 1.

\begin{tabular}{|c|c|c|c|}
\hline Structural part & Material & Specifications & Remarks \\
\hline $\begin{array}{l}\text { Single-layer } \\
\text { Latticed shell }\end{array}$ & Q345B & $\begin{array}{ll}\Phi 180 \times 8 & \Phi 219 \times 10 \\
\Phi 245 \times 10 & \Phi 273 \times 12 \\
\Phi 299 \times 12 & \Phi 325 \times 14 \\
\Phi 351 \times 14 & \Phi 377 \times 16 \\
\Phi 402 \times 16 & \Phi 450 \times 16 \\
\Phi 480 \times 25 & \end{array}$ & $\begin{aligned} E & =206 \times 10^{3} \mathrm{MPa} \\
\mathrm{fy} & =345 \mathrm{MPa}\end{aligned}$ \\
\hline Solder ball & Q345B & $\begin{array}{l}\text { WSR6018 WSR6520 } \\
\text { WSR7022WSR7530 }\end{array}$ & $\begin{array}{l}\text { Gross weight } \\
140 t\end{array}$ \\
\hline Vertical bar & Q345B & $\Phi 180 \times 8$ & $\begin{aligned} E & =206 \times 10^{3} \mathrm{MPa} \\
\mathrm{fy} & =345 \mathrm{MPa}\end{aligned}$ \\
\hline Radial tie rod & Grade 550 & $\Phi 40 、 \Phi 60 、 \Phi 80$ & $\begin{array}{l}\mathrm{E}=206 \times 10^{3} \mathrm{MPa} \\
\mathrm{fy}=550 \mathrm{MPa}\end{array}$ \\
\hline Hoop cables & Grade 1670 & Ф62 $\Phi 78 \quad \Phi 108$ & $\begin{array}{l}\mathrm{E}=160 \times 10^{3} \mathrm{MPa} \\
\text { fy }=1330 \mathrm{MPa}\end{array}$ \\
\hline
\end{tabular}

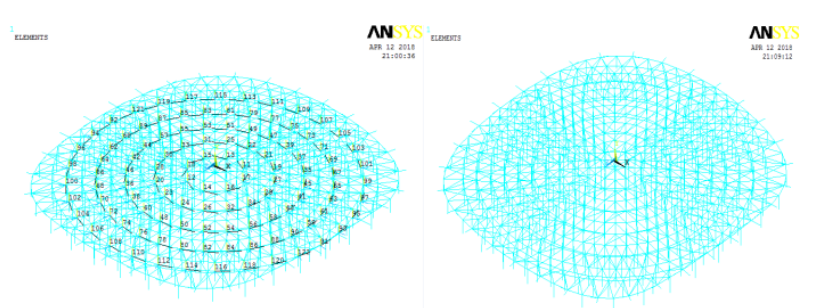


(a)Coupling model $\quad$ (b)Uncoupled model

Fig. 1 Simulation model

\section{Prestressed construction scheme}

In the first batch, the cables are tensioned from the outer ring to the inner ring to $90 \%$ of the initial prestressing force, and in the second batch, the cables are tensioned from the inner ring to the outer ring to $110 \%$ of the initial prestressing force (considering the loss of prestressing force, over tension $10 \%$ ). The design pretension values of each loop cable from the inner ring to the outer ring are $45.21 \mathrm{KN}, 129.96 \mathrm{KN}, 381.78 \mathrm{KN}, 624.92 \mathrm{KN}$ and $1958.89 \mathrm{KN}$ respectively. Therefore, the whole tensioning process is divided into 11 steps: tension the fifth layer of loop cable from the outside to the inside, then pull off the scaffold, and then tension the first layer to the fifth layer of loop cable from inside to outside.

\section{Comparison of initial strain values}

In order to achieve the required prestress value, the external forces applied to the two models are similar. In the process of the first batch of tensioning and the second batch of tensioning, the difference of stress value applied by the adjacent two layers of ring cable is the second and third layers; the difference between the fourth and fifth layers is the largest, and the difference between the other two adjacent layers is small, which indicates that the third and fifth layers of ring cable have a greater impact on the whole structure. The initial strain values applied to each loop during the first and second tensioning are shown in Fig. 2.

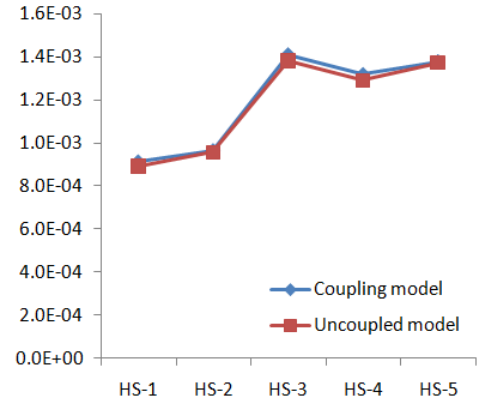

(a)Tension of the first batch

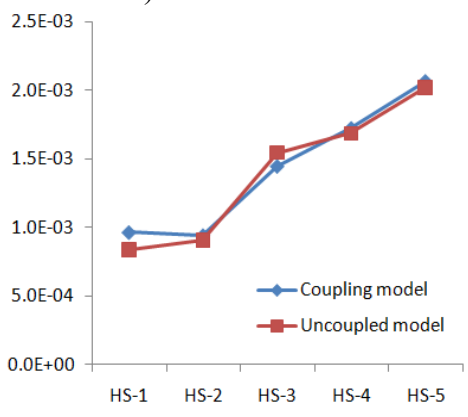

(b)Tension of the second batch

Fig. 2 Initial strain

\section{Internal forces of loop cables}

The internal force of the fifth layer is the largest, which is the key part of the dome structure. When the full scaffold is removed, the internal force of the whole structure will be redistributed due to the weight. The internal force value from the first circle to the third circle will be greatly affected, down $20 \%$; the fourth circle will be down $3 \%$; the fifth circle will be up $10 \%$.The internal force of each loop is shown in Fig.3.

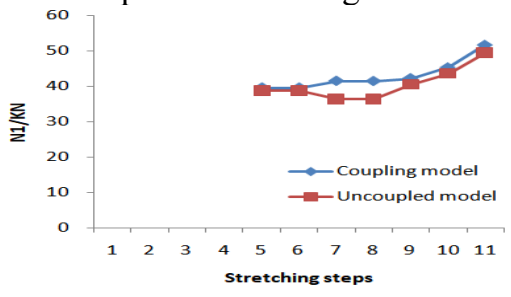

(a) The first ring

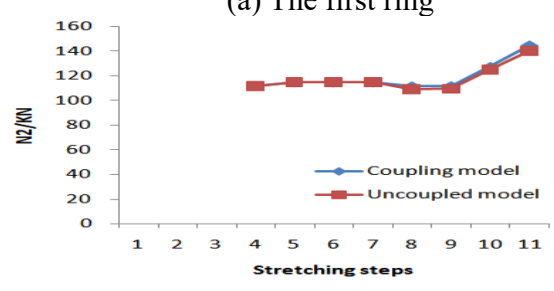

(b) The second ring

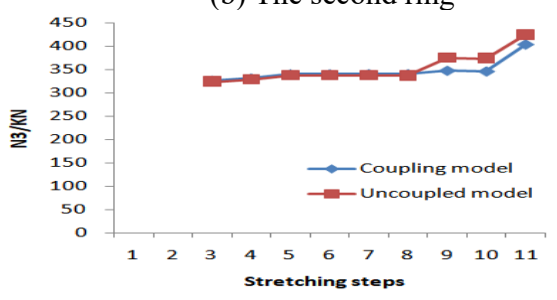

(c) The third ring

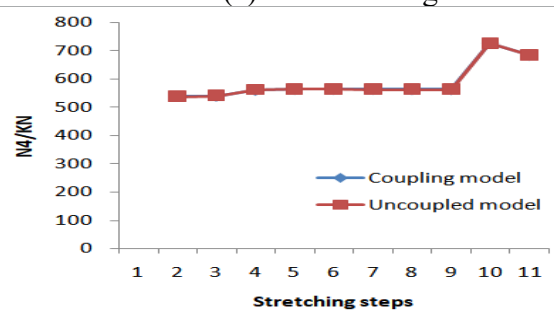

(d) The forth ring

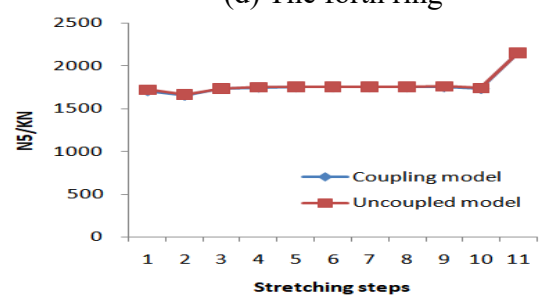

(e) The fifth ring

Fig. 3 Annular cable internal force

\section{Internal forces of radial pull rod}

The sixth tie rod bears the main force of the structure. The internal force of the sixth tie rod of the coupling model is $20 \%$ larger than that of the uncoupled model. It can bear more force in the normal use stage, making the structure safer.

When the scaffold falls off, the internal force of the first, third and fourth ties of the uncoupled model changes greatly, while the internal force of the ties of the coupled model changes little. It shows that the internal 
force of the pull rod of the uncoupled model is greatly affected by the falling frame, and the coupling model can reduce this effect. The internal force of each tie rod is shown in Fig. 4.

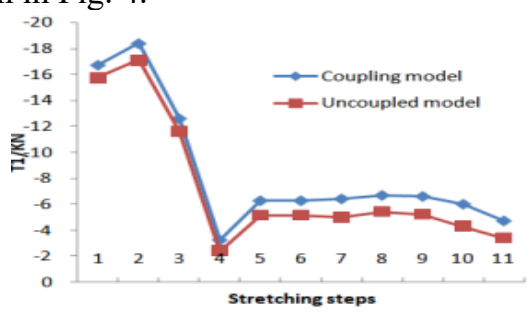

(a)The first tie rod

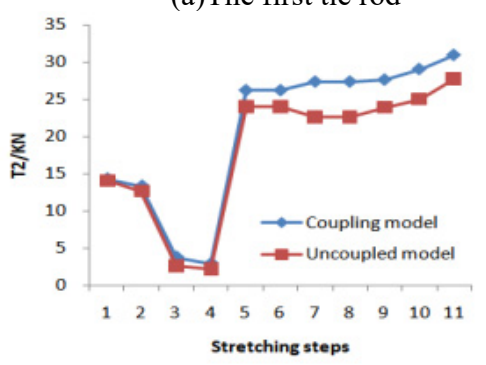

(b)The second tie rod

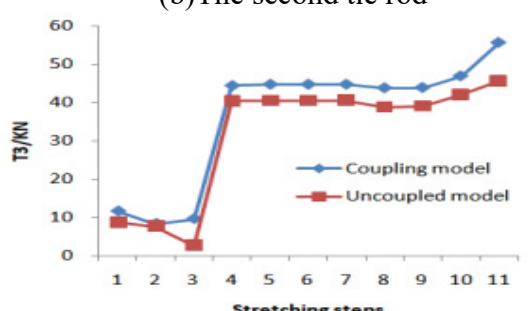

(c) The third tie rod

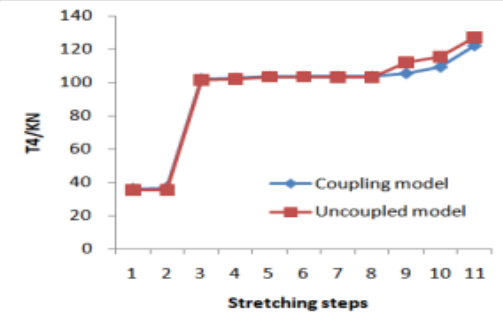

(d)The forth tie rod

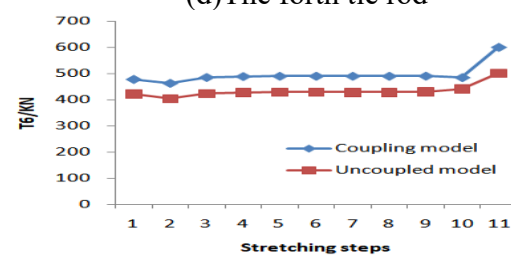

(e)The fifth tie rod

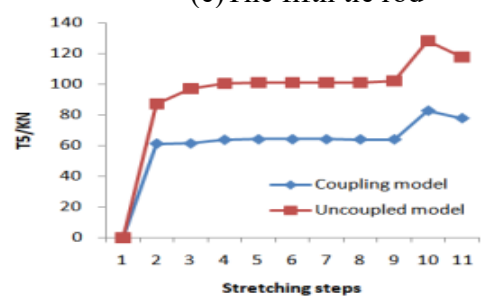

(f)The sixth tie rod

Fig. 4 Internal force of radial pull rod

\section{Internal force analysis of vertical strut}

The fifth circle brace is an important structural member with large internal force. In the two models, the internal force value of the fifth circle brace of the coupling model is $23 \%$ larger than that of the uncoupling model, which shows that the coupling model can make the internal force value of the fifth circle brace larger and the force transmission more efficient. The internal force of each vertical strut is shown in Fig..5.

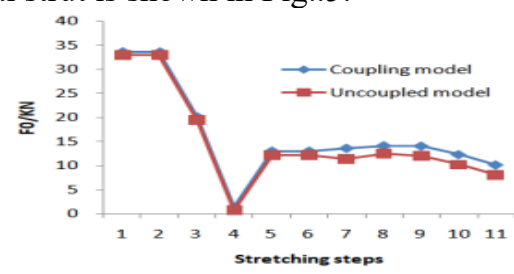

(a)The first vertical strut

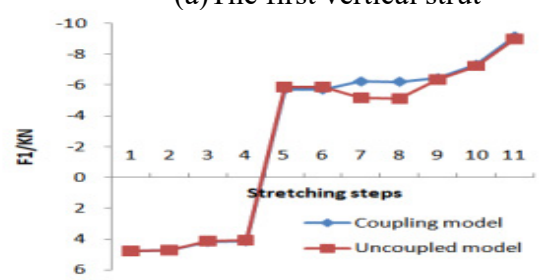

(bThe second vertical strut

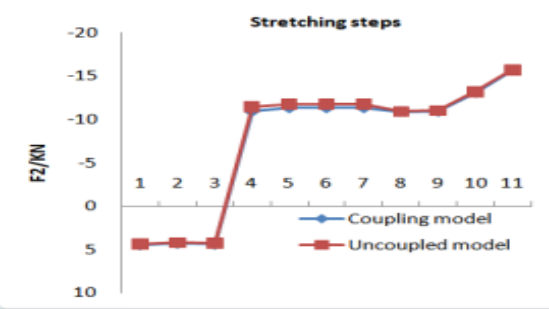

(c)The third vertical strut

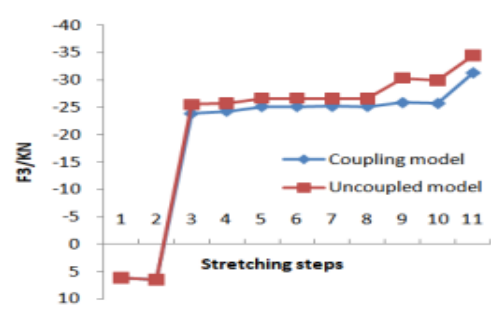

(d) The forth vertical strut

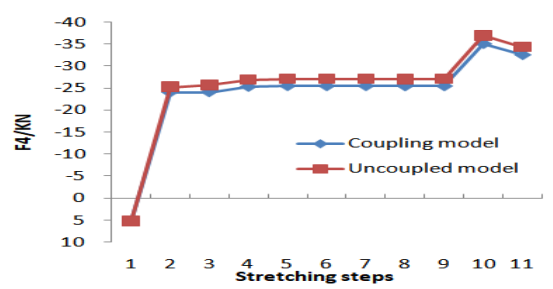

(e) The fifth vertical strut

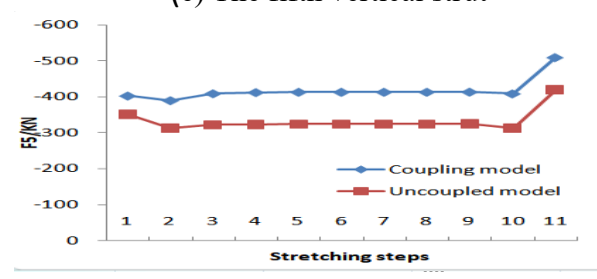

(f) The sixth vertical strut

Fig. 5 Internal force of vertical brace

\section{Conclusions}

(1)Compared with the normal use stage, the structure 
often has the most unfavorable stress condition in the construction process, so it is necessary to establish the finite element model to analyze the construction process.

(2) The establishment of coupling can make the internal force of structure calculation larger and make the structure design more safety oriented.

(3) The effect of scaffold falling off on the structural members from the first circle to the third circle is greater than that of the fourth and fifth circles. The coupling model can effectively reduce the influence of scaffold falling off on the structural internal force.

\section{Acknowledgement}

Supported by Natural Science Foundation of Hebei Province(E2017201158), "one province, one university" special fund, Foundation of Hebei Educational Committee(QN2016171). Innovation and entrepreneurship project of Hebei University.

\section{References}

1. K.R.Shi , Z.X.Guo, B.Luo, et al. Study on the extension and classification of the concept of string dome $[J]$.( Civil engineering)

2. S.Z.Shen, Modern space structure and Olympic stadium construction. (China Engineering Science. 2008)

3. P.Li , S.B.Wang, X.W.Zhao, et al. Prestressed optimization design of double rib ring spherical reticulated shell structure $[J]$. (Shandong University of Architecture,2003)

4. B.Jin, X.X.Zhao, Application and research status of dome structure with string supports [J]. (Architectural technology, 2009)

5. Z.H.Chen, Research progress of string supported structure system [J]. (Architectural structure, 2011)

6. Z.H.Chen, Strung dome structure [M]. (Beijing: Science Press, 2010) 